$b^{3} b^{2}$

Program SIGMA1 (version 79-1): Doppler broaden evaluated cross sections in the evaluated nuclear data file/version $B$ (ENDF/B) format

D. E. Cullen

October 31, 1979

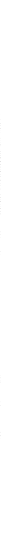




\title{
Program SIGMA1 (version 79-1): Doppler broaden evaluated cross sections in the evaluated nuclear data file/version $B$ (ENDF/B) format
}

\author{
D. E. Cullen \\ Manuscript date: October 31, 1979

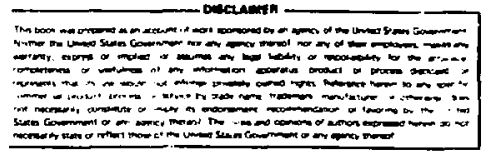

LAWRENCE LIVERMORE LABORATORY University of California $\bullet$ Livermore, California $\bullet 94550$ 
ROREAORD

The total cross-section probability (TCP) systen is designed to process evaluated neutron cross-8ection data into a continuous energy or nultigroup form. The following figure describes the function of each code tn the TCP system by contrasting the form of the data befoce and after code processing.

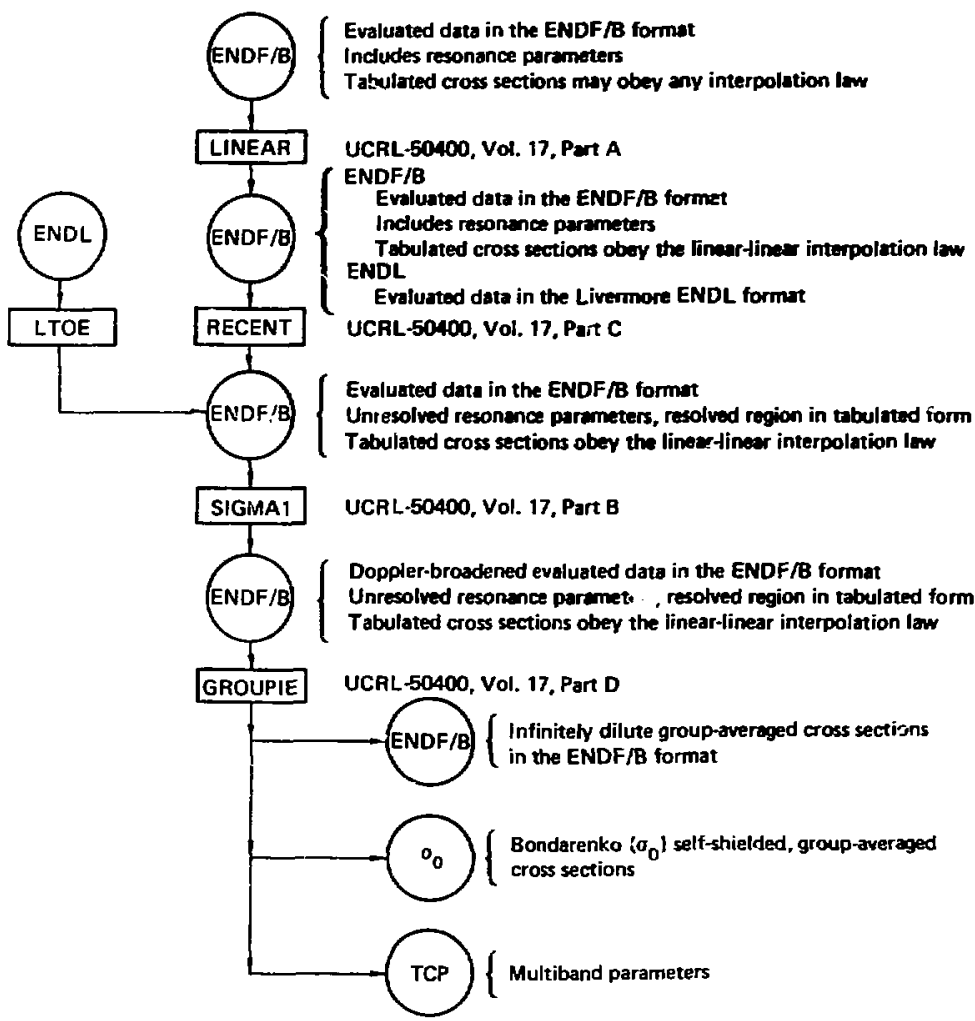

Plots of evaluated cross sections in the ENDF/B format can be obtained at any stage of the above processing by using the EVALPLNT program (OCRL-50400, Vol. 17, Part E). Comparisons between evaiuated cross sections in the RNDF/B format arid experimental data in the ECSIL format call be obtained by using the ECSPIT program (UCRL-50400, Vol. I, Part A). 


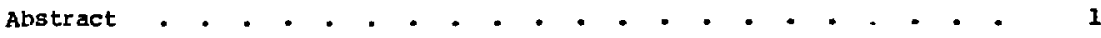

Hew Features in the 1979 Edition . . . . . . . . . . . . . 1

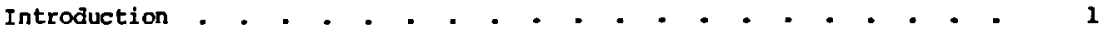

Method . . . . . . . . . . . . . . . . . . . . . . 2

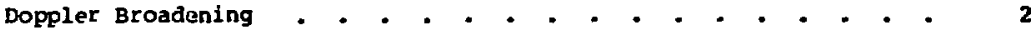

Bootstrapping . . . . . . . . . . . . . . . . 7

Energy Grid for Broadened Cross sections . . - . . . . . . E

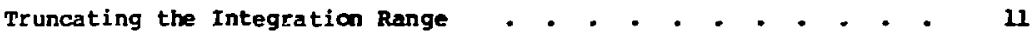

Program Use-General • . . . . . . . . . . . . . . . . 13

Limi tations and Assumptions - . . . . . . . . . . . . 13

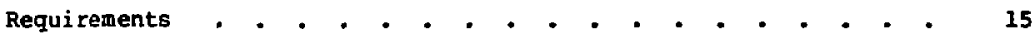

Program Use-Details . . . . . . . . . . . . . . . . . 15

Requesting Evaluated Data for Doppler Broadening . . . . . . 15

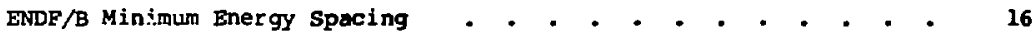

Specifying Maximum Fractional Error - . . • • • . * • . 17

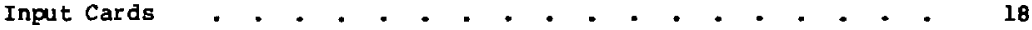

Error Messages . . . . . . • . . . . . . . . . . 18

Input and Output Examples +. - . . . . . . . . . . . . . 20

Example Input . . + . . . . . . . . . . . . . . . 20

Example Output Listing . . . • . . . . . . . . . . . . 21

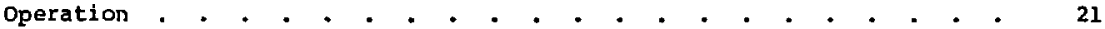

Operation at LL . . . . . . . . . . . . . . . . . . 21

Conversion to other Installations . . . . . . . . . . . 29

Acknowledgments . . . . . . . . • . . . . . . . . . . 30

1978 and 1979 Editions . . . . . . . . . . . . . . . . . . 31

References . . . . . . . . . . . . . . . . . . . . 32 


\begin{abstract}
ABSHRACT
Program SIGMAl Doppler-broadens evaluated cross sections in the ENTF/B format. The program requires that input cross sections be tabulated as inearly interpolable functions of energy in EDF/B File 3; broadened cross sections, in this same form, replace the original values in the output tape. This report describes the methods used in the code and serves as a user's guide. A iisting of the source deck is available on request.
\end{abstract}

\title{
NEN FEATURES IN THE 1979 EDITION
}

The following features are new in the 1979 edition: (1) provizion for an energy-dependent allowable error--this can be used to exphasize energy regions of interest and to reflect the accuracy with which cross sections are known; (2) retrieval of evaluations by up to 100 ranges of $2 A$ or MAT; (3) more accurate representation of output energies by using up to nine digits; (4) versions for the $\mathrm{CDC}-7600$ and the CRAY-1, with standard treatment of I/O by use of subroutines in all programs in the total cross sectior. probability (TCP) system.

\section{TNTRODOCTION}

There exist several widely used, highly detailed libraries of evaluated neutron cross sections. Associated with these libraries are programs that use these data to produce multigroup and continuous Monte Carlo data. For efficiency in coding many of these programs require that cross sections, which are tabulated as functions of energy in the data libraries, be subject to linearlinear interpolation.

The existence or these libraries of evaluated neutron data, and of theit associated computer codes, has made it desirable to develop a code to 
Doppler-broaden linear-1inear tabulated cross sections and to output the results in Iinear-1inear tabulated form. Progran sienl does this.

SIGMI replaces cross sections stored in File 3 of data in the EtoP/B format $^{1}$ with Doppler-broadened cross sections. The BIDF/B tapes nust be run with program LINEAR ${ }^{2}$ befor a runing with sigal to ensure that the File 3 data are linearly interpolable.

\section{HEFEOD}

DOPPLER BROADENIMK

Dopglex broadening, in the context of this report, refers to a change in cross section resulting from thermal motion (translation, rotation, and vibration) of nuclei in a target mat - ial. The srgul nethod ${ }^{3}$ can be used to Doppler-brozden cross sections for any particle (e.g., neutron, proton, deuteron) incident--at nonrelativistic energles--on a target in which the free-atom approximation is val: $d$.

The SIGMAl methas is extensively described in Ref. 3. We briefly descr;be the method below, starting from the well-known free-atom Doppler-broadening equations in which energy $[\mathrm{Eg} .(1)]$ and speed $[\mathrm{Eq} .(2)]$ are the independent variables:

$$
\begin{aligned}
& E^{\frac{1}{5}} \sigma(E, T)=\frac{1}{2}\left(\frac{\alpha}{\pi E}\right)^{\frac{1}{5}} \int_{0}^{\infty}\left[E_{r}^{\frac{1}{2}} \sigma\left(E_{r}, 0\right)\right] \mathrm{dE}_{r}\left\{\exp \left[-\alpha\left(E^{\frac{1}{2}}-E_{r}^{k_{2}}\right)^{2}\right]-\exp \left[-\alpha\left(E^{\frac{1}{2}}+E_{r}^{\frac{1}{2}}\right)^{2}\right]\right\} \\
& v \sigma(v, T)=\frac{1}{v}\left(\frac{\beta}{\pi}\right)^{\frac{1}{r}} \int_{0}^{\infty}\left[v_{r} \sigma\left(v_{r}, 0\right)\right] v_{r} d v_{r}\left\{\exp \left[-\beta\left(v-v_{r}\right)^{2}\right]-\exp \left[-\left(v+v_{r}\right)^{2}\right]\right\} .
\end{aligned}
$$

where

$$
\alpha=\frac{A}{k T}, B=\frac{M}{2 k T}, A=\frac{M}{m},
$$


and

$$
\begin{aligned}
& \text { m = mass of projectile (e.g., neutron, proton, alpha), } \\
& v=\text { projectile velocity. } \\
& v=v=\text { projectile speed, } \\
& E=\frac{1}{2} v^{2}=\text { projectile energy, } \\
& M=\text { target nucleus mass, } \\
& v_{T}=\text { target velocity, } \\
& v_{T}=v_{T}=\text { target speed, } \\
& E_{T}=\frac{1}{2}\left\{v_{T}^{2}=\right.\text { target energy, } \\
& v_{r}=v-v_{T}=\text { relative velocity, } \\
& v_{I}=v_{I}=\text { relative speed, } \\
& E_{I}=\frac{1}{2} \pi v_{I}^{2}=\text { relative energy of projectile as seen by the target, } \\
& \pi(E, 0), \sigma(v, 0)=\operatorname{cold}(D-K) \text { cross sections, and } \\
& \sigma(E, T) \sigma(V, T)=\text { Doppler-broadened cross sections. }
\end{aligned}
$$

BY a change of variables in Eq. (2) so that

$$
y^{2}=\alpha E=\beta v^{2}
$$

and

$$
x^{2}=\alpha E_{t}=\beta v_{L^{2}}^{2}
$$


the equation becomes

$$
\sigma\left(y, T_{2}\right)=\frac{1}{y^{2}}\left(\frac{1}{\pi}\right)^{\frac{1}{2}} \int_{0}^{\infty} x^{2} \sigma\left(x, T_{1}\right)\left\{\exp \left[-(x-y)^{2}\right]-\exp \left[-(x+y)^{2}\right]\right\} d x,
$$

where, for now, $T_{1}=0$ and $T_{2}$ is an arbitrary temperature.

The development below is simplified by defining the quantity

$$
\sigma \star\left(y, T_{2}\right)=\frac{1}{y^{2}}\left(\frac{1}{\pi}\right)^{\frac{1}{2}} \int_{0}^{\infty} x^{2} \sigma\left(x, T_{1}\right) \exp \left[-(x-y)^{2}\right] d x
$$

and noting that the Doppler-broadened cross section is then given by

$$
\sigma\left(Y, T_{2}\right)=\sigma^{\star}\left(Y, T_{2}\right)-\sigma^{\star}\left(-Y, T_{2}\right)
$$

Next we assume that the cross section to be Doppler broadened is given as a table of cross section vs energY, and that values between tabulated points vary linearly with energy and cross section:

$$
\sigma\left(E, T_{I}\right)=\frac{E_{1}-E_{k}}{E_{k+1}-E_{k}} \sigma_{k+1}+\frac{E_{k+1}-E}{E_{k+1}-E_{k}} \sigma_{k}=A_{k}+B_{k} E_{,} \quad E_{k} \leq E \leq E_{k+1},
$$

or

$$
\sigma\left(x, T_{1}\right)=A_{k}+C_{k} x^{2}, \quad x_{k} \leq x \leq x_{k+1} .
$$

Since tabulated cross sections span only a finite energy range (e.g., $10^{-5} \mathrm{ev}$ to $20 \mathrm{MeV}$ ), we also assume that the cross section is continued as constant outside the range of the table. With these two assumptions (data within the enterbY range of the table are linear, data outside the energy range of the table are constant) $\mathrm{Eg}$. (5) becomes

4 


$$
\sigma^{\star}\left(y, T_{2} ;=\frac{1}{y^{2}}\left(\frac{2}{\pi}\right)^{\frac{1}{2}} \sum_{k} \int_{x_{k}}^{x_{k+1}} x^{2}\left(n_{k}+c_{k} x^{2}\right) \exp \left[-(x-y)^{2}\right] d x\right.
$$

By changing variables to $z=x-y$ and collecting terms in porers of $z$ we obtain

$$
\begin{aligned}
& \sigma^{*}\left(y, T_{2}\right)=\frac{1}{y^{2}}\left(\frac{1}{\pi}\right)^{\frac{1}{2}} \sum_{k} \int_{x_{k}-y} \int_{k+1}^{x_{k}-y}\left[c_{k} z^{4}+4 c_{k} z^{3}+\left(A_{k}+6 C_{k} y^{2}\right) z^{2}\right. \\
&\left.+\left(2 A_{k} y+4 C_{k} y^{3}\right) z+\left(A_{k} y^{2}+c_{k} y^{4}\right)\right] \exp \left(-z^{2}\right) d z .
\end{aligned}
$$

Equation (10) can be writter exactly in terms of the functions

$$
H^{n}(a, b)=F^{n}(a)-F^{n}(b)
$$

and

$$
F^{n}(a)=\frac{2}{\pi^{\frac{1}{2}}} \int_{0}^{a} z^{n} \exp \left(-z^{2}\right) d z
$$

with

$$
n=0,1,2,3,4 .
$$

In terms of the $\mathrm{B}^{n} \mathrm{Eq}$. (10) becomes

$$
\begin{aligned}
\sigma^{*}\left(Y, T_{2}\right)=\frac{1}{2 Y^{2}} \sum_{k} C_{k} H^{4}\left(z_{k+1}, z_{k}\right)+4 C_{k} y H^{3}\left(z_{k+1}, z_{k}\right) \\
+\left(A_{k}+6 C_{k} y\right) B^{2}\left(z_{k+1}, z_{k}\right) \\
+\left(2 A_{k} Y+4 C_{k} Y^{3}\right) H^{1}\left(z_{k+1}, z_{k}\right)+\left(z_{k} Y^{2}+C_{k} y^{4}\right) H^{0}\left(z_{k+1}, z_{k}\right),
\end{aligned}
$$


where

$$
\begin{aligned}
& z_{k+1}=x_{k+1}-y, \\
& z_{k}=x_{k}-y .
\end{aligned}
$$

The functions $F^{n}(a)$ satisfy the recursion relation

$$
F^{n}(a)=\frac{(n-1)}{2} F^{n-2}(a)-\left(\frac{1}{\pi}\right)^{\frac{1}{2}} a^{n-1} \exp \left(-a^{2}\right)+\left(\frac{1}{\pi}\right)^{\frac{1}{2}} \delta_{n, 1} \text {. }
$$

where $\delta_{n, I}$ is the kronecker delta.

By evaluating Eg. (12) for $n=0$ and 1 , and by applying the recursion relation with $\mathrm{n}=2,3$, and 4 , we obtain the required functions

$$
\begin{aligned}
& F^{0}(a)=\operatorname{erf}(a), \\
& F^{1}(a)=\left(\frac{1}{\pi}\right)^{\frac{1}{2}}\left[1-\exp \left(-a^{2}\right)\right], \\
& F^{2}(a)=\frac{1}{2} \operatorname{erf}(a)-\frac{a}{\pi^{\frac{1}{2}}} \exp \left(-a^{2}\right), \\
& F^{3}(a)=\left(\frac{1}{\pi}\right)^{\frac{1}{2}}\left[1-\left(1+a^{2}\right) \exp \left(-a^{2}\right)\right],
\end{aligned}
$$

and

$$
F^{4}(a)=\frac{3}{4} \operatorname{erf}(a)-\left(\frac{1}{\pi}\right)^{\frac{1}{2}}\left(\frac{3 a}{2}+a^{3}\right) \exp \left(-a^{2}\right)
$$

This completes the algorithm for determining the Doppler-broadened cross section at any arbitrary energy.

6 
The Doppler-broadening equations can be used to broaden cross sections from $O K$ to a temperature $T \mathrm{~K}$. Suitably generalized, they can also be used to broaden cross sections from any temperature $T_{1}$ to any higher temperature $T_{2}$ (Ref. 4). For example exper imentally measured data at room temperature $(293 \mathrm{~K})$ car be Doppler broadened to $600 \mathrm{~K}$, the resulting data can be broadened to $1000 \mathrm{~K}$, etc. For each of these steps to be independent the Doppler-broadening equations must be in the laboratory systea las opposed to the center-of-nass system) and the above definition of $E_{r}$ nust be used. The generalized equations axe

$$
\begin{aligned}
& v \sigma\left(v, T_{2}\right)=\frac{1}{v}\left(\frac{\beta}{\pi}\right)^{\frac{1}{2}} \int_{0}^{\infty}\left[v_{r} \sigma\left(v_{r}, T_{1}\right)\right] v_{r} d v_{r} \\
& \times\left\{\exp \left[-B\left(v-v_{r}\right)^{2}\right]-\exp \left[-B\left(v+v_{r}\right)^{2}\right]\right\},
\end{aligned}
$$

where

$$
\beta=\frac{M}{2 k\left(T_{2}-T_{1}\right)}
$$

and

$$
\begin{aligned}
E^{\frac{1}{2}} \sigma\left(E, T_{2}\right)=\frac{1}{2}\left(\frac{\alpha}{\pi E}\right)^{\frac{1}{2}} \int_{0}^{\infty}\left[E_{r}^{\frac{1}{2}} \sigma\left(E_{I^{\prime}}, T_{1}\right)\right] d E_{I} \\
\quad \times\left\{\exp \left[-\alpha\left(E^{\frac{1}{2}}-E_{r}^{\frac{1}{2}}\right)^{2}\right]-\exp \left[-\alpha\left(E^{\frac{1}{2}}+E_{r}^{\frac{1}{2}}\right)^{2}\right]\right\},
\end{aligned}
$$

where

$$
\alpha=\frac{A}{k\left(T_{2}-T_{1}\right)}
$$


the $v_{r}$ and $E_{r}$ associated with the cross sections $\sigma\left(v_{r}, T_{1}\right)$ and $\sigma\left(E_{r}, T_{1}\right)$ are the laboratory speed and energy of the profectile, respectively.

\section{ENERGY GRID FOR BROADEATEU CROSS SECTIONS}

If programs that produce multigroup and continucis vonte Carlo data fron evaluated cross section libraries (in which the data are aubject to Iinearlinear interpolation) are to be used with Doppler-broadened cross sections, those cross sections must also be linearly interpolable; large errors can result if they are not. Figure 1 shows the great discrepancy between a $1 / v$ cross section and values obtained by linear-linear interpolation bectween energies that are too far apart. Altbough the Doppler-broadening algorithm described above allows the cross section to be calculated at $3 n y$ given energy, it does not guarantee that the broadened cross section is linearly interpolable between energies.

Ever using the same energy grid that was used to represent the unbroadened cross section can lead to pitfalls. This is because while Doppler broadening smootins out res inance peaks, reducing the number of points needed for linear interpolability, it also introduces a $1 / \nabla$ dependence (which extends to higher and higher projectile energies as the target temperature is iacreased), increasing the number of points needed. Figure 4 shows this effect. For example the $0-R$ elastic cross section for neutrons on hydrogen is roughly constant, at about 20 bazns, between $10^{-5} \mathrm{ev}$ and $1 \mathrm{kev}$, so that the cross section can be linearly interpolated between these energies. When this cross section is broadened to $10000 \mathrm{~K}$ about 50 point? must be inserted between these energies to retain linear interpolability to 18 . (Jn the other hand Doppler broadening makes reaction rates more nearly constant, as well as smoother, so they can be adequately represented on the same energy grid as the cold reaction rates.)

SIGMAl uses the $0-K$ energy grid as the basis for the output energy grid, but inserts energy points as necessary to retain linear interpolability. The use of an interval-halving algorithm to insert the points would be very expensive of computer time. To develop a faster algorithm for inserting points, we assume (as in Fig. 1) a $1 / v$ cross section $\sigma_{1}$, with values $\sigma_{1} v_{1}$ ) $=1 / v_{1}$ and $\sigma_{1}\left(v_{2}\right)=1 / v_{2}$ at the ends of an interval $\left(v_{1}, v_{2}\right)$, and $a$ c1' is section $\sigma_{2}$ 


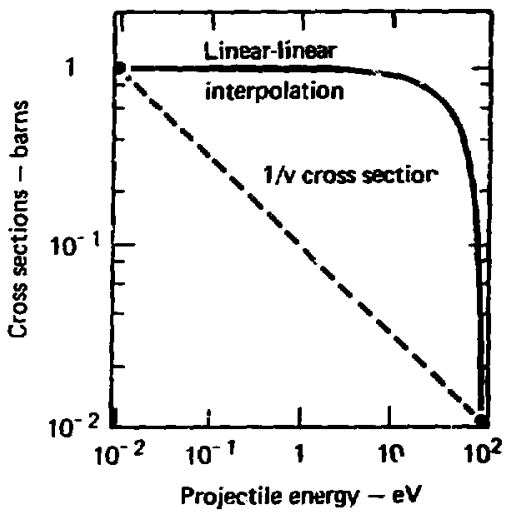

FIG. 1. Comparison of a $1 / 0$ cross section (which appears as a straight line in this log-log plot) with the incorrect cross section that results from linear-iinear interpolation betreen energies that are very far apart.

that obeys inear-linear interpolation in energy and that agrees with $\sigma_{1}$ at the end points. - If we write $v_{2}=S v_{1}$, these two cross sections have the forms

$$
\begin{aligned}
& \sigma_{1}(v)=\frac{1}{v},(1 / v \text { variation }) \\
& \sigma_{2}(v)=\frac{1}{v_{1}}-\frac{\left(v^{2}-v_{1}^{2}\right)}{v_{1}^{3} s(s+1)} \quad\left(\begin{array}{c}
\text { linear-linear in } \\
\text { cross section and energy }
\end{array}\right) .
\end{aligned}
$$

The fractional error at any speed $v$ is

$$
\varepsilon(v)=\frac{\sigma_{1}(v)-\sigma_{2}(v)}{\sigma .(v)}=1-\frac{v^{3}-v_{1}^{2}}{v_{1}^{3} s(s+1)}-\frac{v}{v_{1}} \text {, }
$$


and the derivative of the fractional error with respect to $v$ is

$$
\frac{d \varepsilon}{d v}=\frac{3 v^{2}-v_{1}^{2}}{v_{1}^{3} s(s+1)}-\frac{1}{v_{1}}
$$

The point of maximum $\varepsilon$, and the value of $\varepsilon$ at that point, are thus

$$
v_{\max }=v_{1}\left[\frac{1}{3}\left(1+s+s^{2}\right)\right]^{\frac{1}{2}}
$$

and

$$
E\left(v_{\max }\right)=1-\frac{2}{3}\left(\frac{1}{3}\right)^{1 / 2} \frac{\left(1+s+s^{2}\right)^{3 / 2}}{s(s+1)} \leq 0, \quad v_{1} \leq v \leq v_{2} .
$$

It is clear from Fig. I that $E$ is always a negative quantity.

Note that $\in\left\{v_{\max }\right.$ ' is independent of $v$ and depends only on $s$, the spacing factor between tabulated points. This means that a $1 / y$ variation can be represented $x$ a linear-linear variation in energy, to within fractional error $\epsilon$, simply iy ensuring that successive tabulated energy values are within a factor $s^{2}$ of one another (where $s$ depends on $\varepsilon$, but not on $E$ ). SIGar starts from the same energy points as the $0-K$ data and supplements this grid in any Interva] wher: the points are more widely spaced than a factor $s^{2}$. A thinning algor ithm ${ }^{2}$ then removes points not actually required for limear interpolability.

Table 1 gives the spacing factor [obtained Erom Eq. (20)] required for fractional errors $\varepsilon$ in the range 0.1 to 2.08 . The table also shows the number of points required to space points a factor $\mathrm{s}^{2}$ apart between $10^{-5} \mathrm{ev}$ and $20 \mathrm{MeV}$. For example a tolerance of 0.58 would require 124 points (counting the end points) or roughly 10 per energy decade; the points would be spaced a factor of about $(1.1223)^{2}=1.2596$ apart. 
TABLE 1. Point-spacing requireaents for linear interpolability with a $1 / v$ cross sertion. Por a fractixnal error no greater than $\varepsilon$, energy points aust be space.j a factor $\mathrm{s}^{2}$ apart. To span $10^{-5}$ ev to 20 HeV requires the number of points given (courting end points).

\begin{tabular}{|c|c|c|}
\hline Tolerance $i|\epsilon|$; & Spacing Factor (S) & $\begin{array}{l}\text { Points } \\
\text { required }\end{array}$ \\
\hline 0.001 & 1.0530 & 276 \\
\hline 0.002 & 1.0757 & 195 \\
\hline $0 . \cos$ & 1.0935 & 160 \\
\hline 0.004 & 1.1087 & 139 \\
\hline 0.005 & 1.1223 & 124 \\
\hline 0.006 & 1.1347 & 114 \\
\hline 0.007 & 1.1463 & 105 \\
\hline 0.008 & 1.1571 & 99 \\
\hline $0.1^{n+}$ & 1.1674 & 93 \\
\hline 0.010 & 1.1772 & 88 \\
\hline 0.011 & 1.1865 & 84 \\
\hline 0.012 & 1.1956 & 81 \\
\hline 0.013 & 1.2043 & 78 \\
\hline 0.014 & 1.2128 & 75 \\
\hline 0.015 & 1.2210 & 72 \\
\hline 0.016 & 1.2290 & 70 \\
\hline 0.017 & 1.2367 & 68 \\
\hline 0.018 & 1.2444 & 66 \\
\hline 0.019 & $i .2518$ & 65 \\
\hline 0.020 & 1.2591 & 63 \\
\hline
\end{tabular}

TRUNCATING THE INTEGRATION RANGE

Although the algorithm previously described can evaluate the Dopplerbroadened cross section exactly, this wolld be a costly prosedure since the calculation tine varies as the square of the number of points used co represent each reaction. To reduce the cost, we use the strongly convergent Gaussian character of the Doppler-broadening kernel to truncate the Dopplerbroadening integral of $\mathrm{Eg}$. (15). Because of the exponential term $\exp \left[-(x-y)^{2}\right]$ 
we expect the major contribution to the integral from some interval in centered on $Y$; that is, the integration will be over values of $X$ from $Y-N$ to $Y+N$. A procedure for determining $N$ must recognize that although $\exp \left[-(x-y)^{2}\right]$ is rapidly decreasitiy the tern for $x^{2} \sigma(x, T)$ ny be rapidly increasing; this is particularly true for $\sigma(x, T)$ in the resonance region.

we write the integral of Eq. (5) in truncated form,

$$
\begin{aligned}
\sigma^{\star}\left(y, T_{2}\right)=\frac{1}{y^{2} \pi^{2}} & \int_{0}^{\infty} x^{2} \sigma\left(x, T_{1}\right) \exp \left[-(x-y)^{2}\right] d x \\
& =\frac{1}{y^{2} \pi^{3}} \int_{y-N}^{y+N} x^{2} \sigma\left(x, r_{1}\right) \exp \left[-(x-y)^{2}\right] d x+R(y),
\end{aligned}
$$

where

$$
\begin{aligned}
& R(y)=\frac{1}{y^{2} \pi^{3}} \\
& \left\{\int_{0}^{Y-N} x^{2} \sigma\left(x, T_{1}\right) \exp \left[-(x-y)^{2}\right] d x+\int_{Y+N}^{\infty} x^{2} \sigma\left(x, T_{1}\right) \exp \left[-(x-y)^{2}\right] d x\right\} .
\end{aligned}
$$

We note that

$$
R(y) \leq \frac{1}{y_{\pi}^{2} \frac{y}{2}} \sigma_{\max }
$$

$$
x\left\{\int_{0}^{y-N} x^{2} \exp \left[-(x-y)^{2}\right] d x+\int_{y+N}^{\infty} x^{2} \exp \left[-(x-y)^{2}\right] d x\right\} ;
$$

changing variables (to $z=y-x$ in the first integral and to $z=x-y$ in the second) we obtain

12 


$$
R(y) \leq \frac{1}{y^{2} \pi^{\frac{3}{z}}} \sigma_{\max }\left\{\int_{N}^{y}(y-z)^{2} e^{-z^{2}} d z+\int_{N}^{Y}(y+z)^{2} e^{-z^{2}} d z\right\}
$$

For the filst integral we have

$$
\int_{N}^{y}(y-z)^{2} e^{-z^{2}} d z<\int_{N}^{y}(y+z)^{2} e^{-z^{2}} d z<\int_{N}^{\infty}(y+z)^{2} e^{-z^{2}} d z
$$

so that

$$
R(y) \leq \frac{2}{y^{2} t_{\frac{1}{2}}^{\frac{1}{2}}} \sigma_{\max } \int_{N}^{\infty}(y+z)^{2} e^{-z^{2}} d z
$$

The f cactional ercor made bf truncating at $\mathbf{N}$ is therefore

$$
E(y)=\frac{R(y)}{\sigma(y)} \leq \frac{2}{y^{2} \pi^{\frac{1}{2}}} \frac{\sigma \max }{\sigma(y)} \int_{N}^{\infty}(y+z)^{2} e^{-z^{2}} d z
$$

We ass ume that $\sigma_{\max } f \sigma(y)=10^{4}$, and seek a value of $N$ such that $\varepsilon \leq 0.001$; $\mathrm{N}=4$ accomplishes this safely. Thus the truncated integral should only be extended over those intervals in which at least one end is within four untts of $y$. In particular this means that the second term in Eg. $(6), \sigma \sigma^{\star}\left(-Y, T_{2}\right)$, need not be evaluated at all unless $y \leq 4$.

\section{PROGRAM USE--GENERAL}

\section{LIMITATIONS AND ASSUMPTIONS}

SIGMAl uses only the ENDF/B BCD format (as opposed to binary). It copies all sections except File 3 as Holler:th. The program can therefore be used on data in the ENDF/B-I, II, III, IV or $V$ formats, since all sections of File 3 data are identical in all versions of ENDF/B. 
The prograw reads and Doppler-broadens the data a page at a tine, so there is virtually no limit to the number of points in any section (i.e.., Each reaction wan be described by up to 500000 points).

SIGMAl does not update the reaction index in File 1, Section 451 of each evaluation (see Ref. 1). This will not affect uie user unless he has a program that uses the index to perform random access. In this case program DICTION $^{6}$ shruld be used to create an up-to-date reaction index after sICiAl is used.

Evaluations can be in MAT or ZA order. SIGMAl assumes that the data are in order of inzreasing MAT or $2 \mathrm{~A}$, whichever is used as the retrieval critezion. The program strps searching when it finds ar evaluation with a MAT or $\mathrm{zA}$ value that exceeds the highest requested value.

SIGMAl is written entirely in Portran IV and can be easily modified to run on any medium-sized computer.

SIGMAl requires that input data in the ENDF/B format obey the linearlinear interpolation law; the program will abort if this condition is not met. Program LINEAR ${ }^{2}$ is the best way to linearize data in the ENDF/B format. During Doppler $k$,adening three pages of data are in core at any given time: the page being sroadened, the page below it in energy, and the page above it in energy. If at any time the inteyral extends beyond the limits of these pages, the cross section is extended as constant and a warning message ("EXTENSION") is printed out advising the user of the maximum temperature step allowable to avoic. "EXTENSION." In this case rerun the program, bootstrapping the cross section up to the finai temperature in temperature steps smaller than or equal to the step size recommended in the "axTENSION" message.

The progran selects the energy grid consistent with the input allowable error to avoid problems resulting from the onset of the low-energy $1 / \mathrm{y}$ cross section. If an error of less than $0.1 \%$ is specified it will be used far output thinning, but maximum energy-point spacing will se based on 0.18 .

If the original ENDF/B data are given at a temperature higher than the final temperature, the section will not be Doppler-broadened; the data for the original temperature will be left in the section. If the original dacz are given at a temperature between $0 \mathrm{~K}$ and the final temperature, the program will correctly broaden the data to the final temperature (see Bootstrapping:. 
In the unresolved-resonance region, starting frod energy-averaged cross sections, the SIGMAl algorithm will conserve the averages and return the sant values. SIGKAl does not use unresolved-resonance paranetexs directly.

REQOIREMENTS

The I/0 units are defined as follows:

Filename unit Description

InPUT 5 Input card

OUTPUT 6 Output report

ENDFIN 21 Evaluated data (in the ENDF/B format) to be Doppler brcadened

ENDFOUT 22 Doppler-broadened data (in the FNDE/B format)

SCRSIG 23 scratch Eile

All read and write statements use variable $I / 0$ unit numbers. To convert to any other set of urit numbers, redefine the unit numbers on the program card and ait the beginning of the program (see Appendix).

The program requires approximately 28000 words of core storage on either the $L L L C D C-7600$ or the CRAY-1. The program exscutes approxinately twice as fast on the CRAY-1 as on the CDC-7600. On ti:e CRAY-1, for example, the program requires 0.35 minutes to Doppler-broaden ENDL-78 ${ }^{5}$ Tape 6 from $C$ to $300 \mathrm{~K}$ and to thin the output to 0.18 accuracy. It takes about 4 minutes to Doppler broaden the entire ENDL-7B library (B8 complete evaluations) from 0 to $300 \mathrm{~K}$ and thin the output to 0.18 accuracy.

FROGRAM USE--DETAILS

REQUESTING EVALUATED DATA FOR DOPPLER BROADENING

Evaluations can be requested either by MAT number ${ }^{I}$ or by $2 A$, where $2 A=$ $10002+A$ for an isntope and $\mathrm{zA}=1000 \mathrm{z}$ for an element. Up to 100 ranges of

* The filenames apply to the program at LLL. Disk files with these names will be used by the program. 
MAT or IA can be requested. The ENDF/B data are assumed to be in increasing MAT or $\mathrm{ZA}$ G-der, whichever criterion the user specifies for retrieval. All evaluations that meet the selection criteria w111 be processed by this program; all cther evaluations will be skipped. Processing is ended when an evaluation with a MAT (Or $2 A$ ) is found that exceeds the highest requested value. For example if the user requests all aterials with Mr nubers between 1000 and 1100 , or between 1200 and 1300 , processing is ended as soon as an evaluation with a MAT number higher than 1300 is found; the program assumes the ENDF/B data are in MAT order and does not search any fuzther.

To simplify requests for individual evaluations, as opposed to evaluations in ranges of $\mathrm{NAT}$ or $\mathrm{ZA}$, SIGMAl has been written so that if only a minimum MAT or ZA is specified, only an evaluation with that MAT $r$ zA wils be searched for. For example to prucess ${ }^{238} \mathrm{~d}$, searching by $2 \mathrm{~A}$, one need only specify the lower limit $\mathrm{zA}=92238$ and make no entry for the upper limit. (SE") Input Cards for details-)

SIGMAl outputs the entire evaluation, not just File 3 cross sections; e.g., angular and energy distributions, if present, will aiso be output. Thus the output from this program is complete and in a form that can be used directly in subsequent. processing codes.

ENDF/B MINIMUM ENERGY SPACING

Normally, output in the ENDF/B format that is written with a Fortran write in Ell.4 format yields numbers accurate to 5 digits; e.g., 123.456789 is output as $1.2346 \mathrm{E} \mathrm{2.} \mathrm{For} \mathrm{the} \mathrm{many} \mathrm{narrow} \mathrm{resonances} \mathrm{in} \mathrm{heavy} \mathrm{isotopes} 1$ such as ${ }^{232} \mathrm{Tu}$, $238_{\mathrm{U}}$, and ${ }^{240} \mathrm{pu}$ ) more than 5 digits are needed to distinguish between successive energies (cross sections do not present a problem).

The accuracy of the ENDF/B format has been extended to six digits in many codes--including this one--by writing floating point output in a Ell.4 format that has an additional igit of accuracy instead of the "E"; e.g., 123.456789 is output as $1.23457+2$. This format is called 6-digit ELI.4 format.

In SIGMAl the user can further extend the accuracy of the energy output in the ENDF/B format to as many as nine digits by writing energies $i_{\overline{1}}$ Fortran "F" format. Under this option the format will vary from Fll.B to Fll.0 depending on the energy. For energies between $\mathrm{l} \mathrm{eV}$ and $100 \mathrm{MeV}$ this option gives nine digits of accuracy; for energies between $10^{-3}$ and $1 \mathrm{eV}$ the accuracy 
varies from six to nine digits, which is at least as good as using the 6-digit El1.4 format; below $10^{-3}$ ev and above 100 Hev 6-digit Ell.4 format is used. In SIGMAl, during interval halving, any interval so short that the energies at the two ends of the interval cannot be distinguished is not subdivided further. For example the energies 123.45651 and 123.45749 are indistinguishable in 6-jigit El1.4 ENOF/B output format, in which they are both equal to 1.23457+2; an interval with these energies as endpoints would not be subdivided.

SPECIFYING MAXIMUM FRACTIONAL ERROR

The masimum fractional error used in thinning can be specified by an energy-dependent error law, represented by up to twenty (energy, error? pairs. The energies mist be in ascending order, in ev; errors aust be positive decimal fractions (not percents). If only one pair is given the error is taken as constant for all energies. If more than one pair is yiven the error is taken to vary linearly between tabulated values and to be constant outside of the energy limits given.

For example the following error lav specifies 0.18 accuracy below $100 \mathrm{ev}$, accuracy varying linearly from $0.1 \%$ at $100 \mathrm{ev}$ to 18 at $1 \mathrm{kev}$, and 18 acruracy above $1 \mathrm{kev:}$

$\begin{array}{cc}\text { Anergy, eV } & \text { f cactional error } \\ 0.0 & 0.001 \\ 100.0 & 0.001 \\ 1000 . & 0.01 \\ 1.0 E+10 & 0.01\end{array}$

[The form above makes clear how error is to vary over the entire energy range of interest; however, because of the convention that errors are taken as constant outside the energy range specified, the first and last of the four (energy, error) pairs above could be left out. Thus the error law

\begin{tabular}{|c|c|}
\hline 100.0 & 0.001 \\
\hline 1000.0 & 0.01 \\
\hline
\end{tabular}

is exactly equivalent to the one above, which uses four energy-error pairs.] 
The error law can be used to tailor output for specific applications. For example the error law given above can be used to obtain very accurate (0.14) cross sections for ${ }^{238} \mathrm{v}$ and yet minimize the number of data points used to represent the many narrow resonances between about 1 and 3 keV.

INEUT CARDS

\begin{tabular}{|c|c|c|c|}
\hline Card & Columng & Format & Description \\
\hline \multirow[t]{3}{*}{1} & $1-11$ & 111 & $\begin{array}{l}\text { Retrieval criterion }(0 \text { indicates MAT, } 1 \\
\text { indicates } \mathrm{zA} \text { ). }\end{array}$ \\
\hline & $12-22$ & I11 & $\begin{array}{l}\text { Minimu energy spacing (0 indicates 6-digit } \\
\text { ninimum energy spacing for calaulations, } \\
\text { 6-digit El1.4 output; } 1 \text { indicates 9-digit } \\
\text { minimum energy spacing for calculations, } \\
\text { 6-digit Ell.4 output; } 2 \text { indicates 9-digit } \\
\text { minimum energY spacing for calculations, } \\
\text { variable 9-digit F format output). }\end{array}$ \\
\hline & $23-33$ & B11.4 & Output Kelvin temperature. \\
\hline \multirow[t]{2}{*}{ vary } & $1-11$ & Ill & Minimum MAT or ZA. \\
\hline & $12-22$ & Ill & $\begin{array}{l}\text { Maximum MAT or zA (blank, for single } \\
\text { evaluation). Op to } 100 \text { MAT or zA ranges can } \\
\text { be specified, one range per card. The list } \\
\text { is terminated by a blank card. }\end{array}$ \\
\hline \multirow[t]{2}{*}{ vary } & $1-11$ & $E 11.4$ & Energy for Eile 3 error law. \\
\hline & $12-22$ & E11.4 & Error for File 3 error law. \\
\hline
\end{tabular}

The File 3 error law can be described by up to 20 (energy, error) pairs, one pair per card. The input for the law is terminated by a blank card. If only one point is given the error law is assumed to be constant over the entire range. The energies must be in ascending order, in ev; errors must be positive decimal fractions (not percents).

ERROR MESSAGES

1.

EXTENSION

CROSS SECTION EXTENSION CAN BE AVOIDED BY THINNING DATA OR DOPPLER BROADENTNG IN STEPS OF IESS THAN 2.7419+6 KELVIN 
The Doppler integrals have extended beyond the three pages of data in core. This normally occurs only for large temperature changes. Doppler broaden to the final temperature in steps (in the above example each step must be smallex than about $2.7 \times 10^{6} \mathrm{R}$ ).

2. INTERPOLATIOAT LAW IS NOT LINEAR-LINEAR ***EXECUTION TERMINATED** *

The data in the ENDF/B format must be subject to linear-linear interpolation for valid Doppler broadening by SIGUAl. Convert the data to linear-linear form with program LINEAR. 2

3. SCRATCH MAXIMUM PAGE COUNT EXCEEDED $\star \star \star$ EXECUTION TERMINATED $* \star \star$

The scratch disk file is designed to allow each section to include up to 500000 points. This error message is printed out in the unlikely event that this limit is exceeded.

4. OVER 200 RANGES--EXECUTION TERMINATED

A maximum of 100 MAT or $2 A$ ranges is allowed.

5. OVER 20 RANGES--EXECUTION TERMINATED

The error law may be described by no more than 20 (energy, error) pairs.

6. ERROR MUST BE POSITIVE--EXBCUTION TERMINATED

Iteration will not converge unless the errors in the error law are positive.

7. ENERGIES MUST BE IN ASCENDING ORDER--EXECUTION TERMINATED

8. ENDFIN INITIALIZATION ERROR

9. ENDFOUT CLOSING ERROR

10. SCRSIG DESTROY ERROR

These errors indicate that the program is having trouile locating, creating, closing, or destroying a disk file. If the program cannot 
Initialize ENDFIN it indicates the BNDF/B fornat data is either not on disk or has the wrong filename. If the progran cannot initialize Eapour or scrsig it is baving trouble locating disk space in order to create a file; it will keep trying.

11. SCRATCH I/O ERROT.-EXECUTION TERHITATTED

This can only occur if an evaluation generates more than 500000 data points and exceeds the present disk file allocation of 1000000 words, or if there is a computer problen. In the former case increase the allowable error, so as to generate fewer points, and re-run. In the latter case try again.

\section{INPUT AND OUTPUT EXAYPLES}

EXAMPLE INPUT

The input cards shown below correspond to the following problem:

Consider ${ }^{235} \mathrm{U}$, which is MAT 1261. Fe':rieve it by MAT number. Use 9digit energy spacing for the accuracy of the calculation, and 6-digit output. Doppler broaden the data to $300 \mathrm{~K}$. Insert data points and thin tc the following accuracies: between 0 and $100 \mathrm{ev}$ use 0.1 accuracy; between $100 \mathrm{ev}$ and $1 \mathrm{keV}$ Viry accuracy between 9.1 and 1.08; above $1 \mathrm{keV}$ use 18 accuracy.

The required input cards are

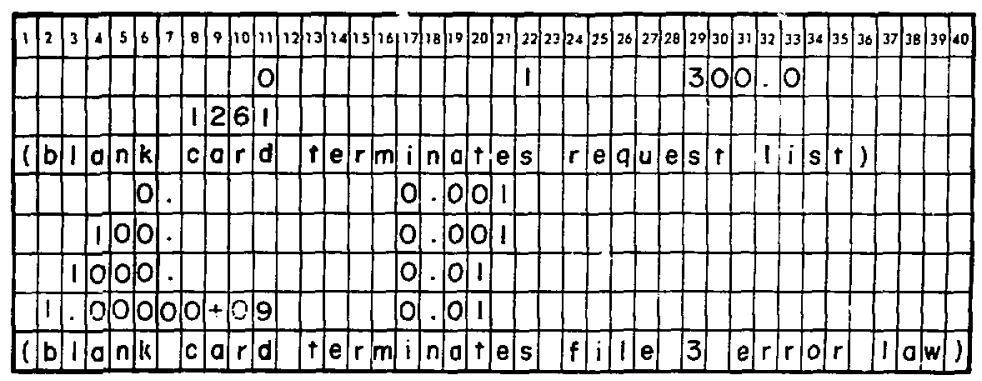


The following listing results from Doppler broadening ExDI-76 Tape 6 to $300 \mathrm{R}$ and thinning the output to 0.1 . Figures 2 through 5 11lustrate the wide range of applications of the sienal code:

- Fig. 2 shows broadening of the ${ }^{233} \mathrm{v}$ total cross section to reactor-core texperatures $(300-10000 \mathrm{~K})$.

- Fig. 3 shows broadening of the ${ }^{233} \mathrm{v}$ total cross section to controlled-thermonuciear-reactor (CTR) and stellar temperatures (1 ev--10 kev)".

- Fig. 4 shows broadening of a constant aross section at $0 \mathrm{~K}$ to temperatures ranging from $1 \mathrm{ev}$ to $1 \mathrm{HeV}$.

- Fig. 5 shows broadening of a $1 / v$ cross section at $0 \mathrm{k}$ to temperatures renging from $1 \mathrm{eV}$ to $1 \mathrm{MeV}$.

OPERATION

OPRARATION AT LIL

At Livermore compiled, loaded, ready-to-execute versions of this program are available from the photostore file for either the CDC-7600, with the command

\section{.193025 : PRograms [SIGMAI INSIGMAI].}

or for the CRAY-1, with tha command

$$
.193025 \text { : PRO TRAMS:CRAY-1 [SIGMAI INSIGMAI]. }
$$

\footnotetext{
* Some readers may be unfamiliar with the practice of expressing temperatures in ev, which arises because the dimension of $\mathrm{kT}$ is energy. Fcom Boltzmann's constant $k=1.38 \times 10^{-23}$ joule per Relvin $=8.62 \times 10^{-5} \mathrm{eV}$ per Kelvin we obtain, e.g., the equivalences $\mathrm{leV} \approx 12000 \mathrm{~K}$ and $10 \mathrm{keV} \approx 1.2 \times 10^{8} \mathrm{k}$.
} 
I OOPPLER BROADEN ENDF /B CROSS SECTIONS (SIGMAI 79-I)

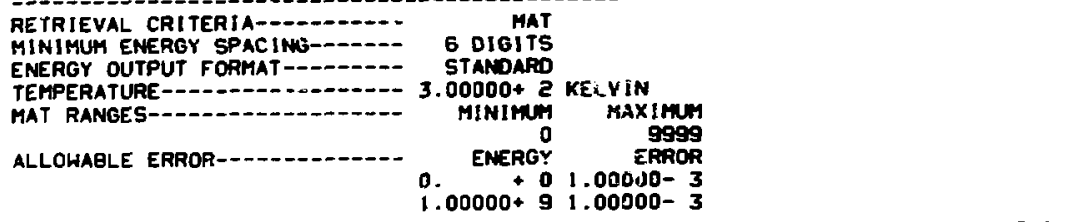

TAPE LAEEL

LAHRENCE LIVERMORE EVALUATEO LJERARY (ENOL) 6/01/78

\begin{tabular}{|c|c|c|c|c|c|c|c|c|}
\hline ZA & MAT & MT & & $\begin{array}{r}\text { KELVIN } \\
\text { IN }\end{array}$ & G-VA & LUE & $\begin{array}{r}\text { POINTS } \\
\text { IN }\end{array}$ & $\begin{array}{l}\text { POINTS } \\
\text { OUT }\end{array}$ \\
\hline $\begin{array}{l}90231 \\
90231 \\
90231 \\
90231 \\
90231 \\
90231 \\
90231 \\
90231 \\
90231 \\
90231 \\
90231 \\
90231\end{array}$ & $\begin{array}{l}7863 \\
7863 \\
7863 \\
7863 \\
7653 \\
7863 \\
7863 \\
7663 \\
7863 \\
7863 \\
7963 \\
7863\end{array}$ & $\begin{array}{r}1 \\
4 \\
16 \\
17 \\
18 \\
37 \\
91 \\
102 \\
251 \\
252 \\
253\end{array}$ & $\begin{array}{l}0 . \\
0 . \\
0 . \\
0 . \\
0 . \\
0 . \\
0 . \\
0 . \\
0 . \\
0 . \\
0 . \\
0 .\end{array}$ & $\begin{aligned}+ & 0 \\
+ & 0 \\
+ & 0 \\
+ & 0 \\
+ & 0 \\
+ & 0 \\
+ & 0 \\
+ & 0 \\
+ & 0 \\
+ & 0 \\
+ & 0 \\
+ & 0\end{aligned}$ & $\begin{array}{l}0 . \\
0 . \\
0 . \\
-5.12000 \\
-1.19100 \\
1.80000 \\
-1.71500 \\
0 . \\
6.43000 \\
0 . \\
0 . \\
0 .\end{array}$ & $\begin{array}{r}+0 \\
+0 \\
+0 \\
+\quad 6 \\
+\quad 7 \\
+8 \\
+\quad 7 \\
+0 \\
+0 \\
+\quad 0 \\
+0 \\
+0 \\
+\end{array}$ & $\begin{array}{r}246 \\
43 \\
22 \\
19 \\
11 \\
152 \\
5 \\
22 \\
138 \\
20 \\
20 \\
20\end{array}$ & $\begin{array}{r}220 \\
72 \\
22 \\
19 \\
11 \\
195 \\
4 \\
22 \\
183 \\
20 \\
19 \\
19\end{array}$ \\
\hline & & & & & MAT TOT & ALS & 718 & 806 \\
\hline $\begin{array}{l}90232 \\
96232 \\
90232 \\
90232 \\
90232 \\
90232 \\
90232 \\
90232 \\
90232 \\
90232 \\
90232 \\
90232\end{array}$ & $\begin{array}{l}7864 \\
7864 \\
7864 \\
7864 \\
7864 \\
7864 \\
7864 \\
7864 \\
7864 \\
7864 \\
7864 \\
7864\end{array}$ & $\begin{array}{r}1 \\
2 \\
4 \\
16 \\
17 \\
18 \\
37 \\
91 \\
102 \\
251 \\
252 \\
253\end{array}$ & $\begin{array}{l}0 . \\
0 . \\
0 . \\
0 . \\
0 . \\
0 . \\
0 . \\
0 . \\
0 . \\
0 . \\
0 . \\
0 .\end{array}$ & $\begin{aligned} &+ 0 \\
&+ 0 \\
&+ 0 \\
&+ 0 \\
&+ 0 \\
&+0 \\
&+0 \\
&+0 \\
&+0 \\
&+0 \\
&+0 \\
&+0\end{aligned}$ & $\begin{array}{l}0 . \\
0 . \\
0 . \\
-6.34000 \\
-1.15600 \\
1.70000 \\
-1.83500 \\
0 . \\
4.79000 \\
0 . \\
0 . \\
0 .\end{array}$ & $\begin{array}{l}+0 \\
+0 \\
+0 \\
+0 \\
+6 \\
+\quad 7 \\
+8 \\
+\quad 7 \\
+0 \\
+6 \\
+0 \\
+0 \\
+0\end{array}$ & $\begin{array}{r}6261 \\
2993 \\
62 \\
17 \\
8 \\
34 \\
2 \\
62 \\
5535 \\
14 \\
14 \\
14\end{array}$ & $\begin{array}{r}5323 \\
2858 \\
51 \\
16 \\
8 \\
34 \\
2 \\
51 \\
5451 \\
13 \\
14 \\
13\end{array}$ \\
\hline & & & & & MAT TOTA & ALS & 15006 & 13874 \\
\hline $\begin{array}{l}90233 \\
90233 \\
90233 \\
90233 \\
90233 \\
90233 \\
90233 \\
90233 \\
90233 \\
90233 \\
90233 \\
90233\end{array}$ & $\begin{array}{l}7865 \\
7865 \\
7865 \\
7865 \\
7865 \\
7865 \\
7865 \\
7365 \\
7865 \\
7865 \\
7865 \\
.7865\end{array}$ & $\begin{array}{r}1 \\
2 \\
4 \\
16 \\
17 \\
18 \\
37 \\
91 \\
102 \\
751 \\
252 \\
253\end{array}$ & $\begin{array}{l}0 . \\
0 . \\
0 . \\
0 . \\
0 . \\
0 . \\
0 . \\
0 . \\
0 . \\
0 . \\
0 . \\
0 .\end{array}$ & $\begin{aligned}+ & 0 \\
+ & 0 \\
+ & 0 \\
+ & 0 \\
+ & 0 \\
+ & 0 \\
+ & 0 \\
+ & 0 \\
+ & 0 \\
+ & 0 \\
+ & 0 \\
+ & 0\end{aligned}$ & $\begin{array}{l}0 . \\
0 . \\
0 . \\
-4.78000 \\
-1.12200 \\
1.80000 \\
-1.63400 \\
0 . \\
6.18000 \\
0 . \\
0 . \\
0 .\end{array}$ & $\begin{array}{l}+0 \\
+0 \\
+0 \\
+6 \\
+7 \\
+8 \\
+7 \\
+0 \\
+6 \\
+0 \\
+0 \\
+0\end{array}$ & $\begin{array}{r}296 \\
43 \\
21 \\
19 \\
14 \\
130 \\
5 \\
21 \\
121 \\
16 \\
16 \\
16\end{array}$ & $\begin{array}{r}219 \\
72 \\
21 \\
19 \\
14 \\
174 \\
4 \\
21 \\
157 \\
15 \\
15 \\
16\end{array}$ \\
\hline
\end{tabular}




\begin{tabular}{|c|c|c|c|c|c|c|c|c|c|}
\hline $\begin{array}{l}92233 \\
92233 \\
92233 \\
92233 \\
92233 \\
92233 \\
92233 \\
92233 \\
92233 \\
92233 \\
92233\end{array}$ & $\begin{array}{l}7866 \\
7866 \\
7866 \\
7866 \\
7866 \\
7966 \\
7866 \\
7866 \\
7866 \\
7966 \\
7866\end{array}$ & $\begin{array}{r}1 \\
2 \\
4 \\
16 \\
17 \\
18 \\
91 \\
102 \\
251 \\
252 \\
253\end{array}$ & $\begin{array}{l}0 . \\
0 . \\
0 . \\
0 . \\
0 . \\
0 . \\
0 . \\
0 . \\
0 . \\
0 . \\
0 .\end{array}$ & $\begin{array}{l}+0 \\
+0 \\
+0 \\
+0 \\
+0 \\
+0 \\
+0 \\
+0 \\
+0 \\
+0 \\
+0\end{array}$ & $\begin{array}{l}0 . \\
0 . \\
0 . \\
-5.90000 \\
-1.31800 \\
1.80000 \\
0 . \\
6.84000 \\
0 . \\
0 . \\
0 .\end{array}$ & $\begin{aligned} &+ 0 \\
&+ 0 \\
&+ 0 \\
& 0+ 6 \\
& 0+ 7 \\
&+ \theta \\
&+0 \\
&+ \\
&+ \\
&+0 \\
&+0 \\
&+0\end{aligned}$ & $\begin{array}{r}2084 \\
343 \\
32 \\
12 \\
6 \\
1613 \\
39 \\
1954 \\
21 \\
21 \\
21\end{array}$ & $\begin{array}{r}2353 \\
352 \\
30 \\
11 \\
5 \\
1608 \\
30 \\
1949 \\
21 \\
21 \\
20\end{array}$ & \\
\hline & & & & & MAT TOT & TAL & 6939 & 6400 & \\
\hline $\begin{array}{l}92234 \\
92234 \\
92234 \\
92234 \\
92234 \\
92234 \\
92234 \\
92234 \\
92234 \\
92234 \\
92234\end{array}$ & $\begin{array}{l}7867 \\
7867 \\
7867 \\
7867 \\
7867 \\
7867 \\
7867 \\
7867 \\
7867 \\
7867 \\
7867\end{array}$ & $\begin{array}{r}1 \\
2 \\
4 \\
16 \\
17 \\
18 \\
91 \\
102 \\
251 \\
252 \\
253\end{array}$ & $\begin{array}{l}0 . \\
0 . \\
0 . \\
0 . \\
0 . \\
0 . \\
0 . \\
0 . \\
0 . \\
0 . \\
0 .\end{array}$ & $\begin{aligned} &+ 0 \\
&+ 0 \\
&+ 0 \\
&+ 0 \\
&+ 0 \\
&+0 \\
&+0 \\
&+0 \\
&+0 \\
&+0 \\
&+0\end{aligned}$ & $\begin{array}{l}0 . \\
0 . \\
0 . \\
-6.84000 \\
-1.25900 \\
1.80000 \\
0 . \\
5.31000 \\
0 . \\
0 . \\
0 .\end{array}$ & $\begin{aligned} &+ 0 \\
&+ 0 \\
&+ 0 \\
&+ 6 \\
&+ 7 \\
&+ 0 \\
&+0 \\
&+6 \\
&+0 \\
&+0 \\
&+0\end{aligned}$ & $\begin{array}{r}189 \\
37 \\
19 \\
13 \\
7 \\
40 \\
19 \\
129 \\
29 \\
29 \\
29\end{array}$ & $\begin{array}{r}190 \\
57 \\
17 \\
13 \\
7 \\
40 \\
17 \\
166 \\
28 \\
29 \\
27\end{array}$ & \\
\hline & & & & & HAT TOT & ALS & 538 & $39 !$ & \\
\hline $\begin{array}{l}92235 \\
92235 \\
92235 \\
92235 \\
92235 \\
92235 \\
92235 \\
92235 \\
92235 \\
92235 \\
92235 \\
92235\end{array}$ & $\begin{array}{l}7868 \\
7868 \\
7868 \\
7868 \\
7868 \\
7868 \\
7868 \\
7868 \\
7868 \\
7868 \\
7868 \\
7968\end{array}$ & $\begin{array}{r}1 \\
2 \\
4 \\
16 \\
17 \\
18 \\
37 \\
91 \\
102 \\
251 \\
252 \\
253\end{array}$ & $\begin{array}{l}0 . \\
0 . \\
0 . \\
0 . \\
0 . \\
0 . \\
0 . \\
0 . \\
0 . \\
0 . \\
0 . \\
0 .\end{array}$ & $\begin{array}{l}+0 \\
+0 \\
+0 \\
+0 \\
+0 \\
+0 \\
+0 \\
+0 \\
+0 \\
+0 \\
+0 \\
+0\end{array}$ & $\begin{array}{l}0 . \\
0 . \\
0 . \\
-5.230 \mathrm{C} \\
-1.200 \mathrm{C} \\
1.90000 \\
-1.78900 \\
0 . \\
5.55000 \\
0 . \\
0 . \\
0 .\end{array}$ & $\begin{array}{rl}+ & 0 \\
+ & 0 \\
+ & 0 \\
+ & 6 \\
+ & 7 \\
+ & 9 \\
+ & 7 \\
& 0 \\
1 & 6 \\
+ & 0 \\
+ & 0 \\
+ & 0\end{array}$ & $\begin{array}{r}2294 \\
235 \\
25 \\
16 \\
7 \\
1511 \\
3 \\
25 \\
767 \\
29 \\
29 \\
29\end{array}$ & $\begin{array}{r}2292 \\
284 \\
25 \\
16 \\
7 \\
1505 \\
3 \\
25 \\
037 \\
27 \\
29 \\
27\end{array}$ & \\
\hline & & & & & MAT TOT & ALS & 4970 & 5137 & \\
\hline $\begin{array}{l}92236 \\
92236 \\
92236 \\
92236 \\
92236 \\
92236 \\
92236 \\
92236 \\
92236 \\
92236 \\
92236\end{array}$ & $\begin{array}{l}7869 \\
7869 \\
7869 \\
7869 \\
7869 \\
7869 \\
7869 \\
7869 \\
7869 \\
7869 \\
7869\end{array}$ & $\begin{array}{r}1 \\
2 \\
4 \\
16 \\
17 \\
18 \\
91 \\
102 \\
251 \\
252 \\
253\end{array}$ & $\begin{array}{l}0 . \\
0 . \\
0 . \\
0 . \\
0 . \\
0 . \\
0 . \\
0 . \\
0 . \\
0 . \\
0 .\end{array}$ & $\begin{array}{l}+0 \\
+0 \\
+0 \\
+0 \\
+0 \\
+0 \\
+0 \\
+0 \\
+0 \\
+0 \\
+0\end{array}$ & $\begin{array}{l}0 . \\
0 . \\
0 . \\
-6.55000 \\
-1.18500 \\
1.80000 \\
0 . \\
5.12000 \\
0 . \\
0 . \\
0 .\end{array}$ & $\begin{aligned}+ & 0 \\
+ & 0 \\
+ & 0 \\
+ & 6 \\
+ & 7 \\
+ & 8 \\
+ & 0 \\
1+ & 6 \\
+ & 0 \\
+ & 0 \\
+ & 0\end{aligned}$ & $\begin{array}{r}179 \\
35 \\
21 \\
14 \\
8 \\
40 \\
21 \\
127 \\
29 \\
29 \\
29\end{array}$ & $\begin{array}{r}176 \\
59 \\
19 \\
14 \\
8 \\
71 \\
19 \\
183 \\
28 \\
29 \\
28\end{array}$ & $\hat{f}$ \\
\hline & & & & & MAT TOT & ALS & 532 & 633 & \\
\hline
\end{tabular}




\begin{tabular}{|c|c|c|c|c|c|c|c|c|}
\hline $\begin{array}{l}93237 \\
93237 \\
93237 \\
93237 \\
93237 \\
93237 \\
93237 \\
93237 \\
93237 \\
93237 \\
93237\end{array}$ & $\begin{array}{l}1263 \\
1263 \\
1263 \\
1263 \\
1263 \\
1263 \\
1263 \\
1263 \\
1263 \\
1263 \\
1263\end{array}$ & $\begin{array}{r}56 \\
57 \\
59 \\
59 \\
60 \\
61 \\
91 \\
102 \\
251 \\
252 \\
253\end{array}$ & $\begin{array}{l}0 . \\
0 . \\
0 . \\
0 . \\
0 . \\
0 . \\
0 . \\
0 . \\
0 . \\
0 . \\
0 .\end{array}$ & $\begin{array}{l}+0 \\
+0 \\
+0 \\
+0 \\
+0 \\
+0 \\
+0 \\
+0 \\
+0 \\
+0 \\
+0 \\
+0\end{array}$ & $\begin{array}{l}-2.24000 \\
-2.66000 \\
-3.05000 \\
-3.32600 \\
-3.69000 \\
-3.71000 \\
-3.32000 \\
5.49000+ \\
0 . \\
0 . \\
0 .\end{array}$ & $\begin{array}{r}+5 \\
+5 \\
+5 \\
+5 \\
+5 \\
+5 \\
+5 \\
+5 \\
+5 \\
+5 \\
+0 \\
+\end{array}$ & $\begin{array}{r}30 \\
27 \\
25 \\
24 \\
21 \\
19 \\
128 \\
316 \\
39 \\
39 \\
39\end{array}$ & $\begin{array}{r}25 \\
24 \\
23 \\
20 \\
19 \\
17 \\
70 \\
214 \\
38 \\
37 \\
39\end{array}$ \\
\hline & & & & & HAT TOTA & ALS & 2171 & 1392 \\
\hline $\begin{array}{l}22000 \\
22000 \\
22000 \\
22000 \\
22000 \\
22000 \\
22000 \\
22000 \\
22000 \\
22000\end{array}$ & $\begin{array}{l}1286 \\
1286 \\
1286 \\
1286 \\
1286 \\
1286 \\
1286 \\
1286 \\
1286 \\
1286\end{array}$ & $\begin{array}{r}1 \\
2 \\
3 \\
4 \\
16 \\
51 \\
91 \\
102 \\
103 \\
107\end{array}$ & $\begin{array}{l}0 . \\
0 . \\
0 . \\
0 . \\
0 . \\
0 . \\
0 . \\
0 . \\
0 . \\
0 .\end{array}$ & $\begin{aligned}+ & 0 \\
+ & 0 \\
+ & 0 \\
+ & 0 \\
+ & 0 \\
+ & 0 \\
+ & 0 \\
+ & 0 \\
+ & 0 \\
+ & 0\end{aligned}$ & $\begin{array}{r}0 . \\
0 . \\
0 . \\
-2.44000+ \\
-1.16300+ \\
-9.87000 \\
-2.44000 \\
6.14000 \\
-3.21000 \\
-2.03000\end{array}$ & $\begin{array}{l}0 \\
0 \\
0 \\
5 \\
7 \\
5 \\
5 \\
6 \\
6 \\
6\end{array}$ & $\begin{array}{r}1305 \\
913 \\
444 \\
48 \\
6 \\
39 \\
17 \\
395 \\
8 \\
6\end{array}$ & $\begin{array}{r}1043 \\
999 \\
397 \\
47 \\
6 \\
38 \\
16 \\
390 \\
8 \\
6\end{array}$ \\
\hline & & & & & MAT TOTA & LS & 3181 & 2849 \\
\hline $\begin{array}{l}42000 \\
42000 \\
42000 \\
42000 \\
42000 \\
42000 \\
42000 \\
42000 \\
42000 \\
42000\end{array}$ & $\begin{array}{l}1287 \\
1287 \\
1287 \\
1287 \\
1287 \\
1287 \\
1297 \\
1287 \\
1287 \\
1287\end{array}$ & $\begin{array}{r}1 \\
2 \\
4 \\
16 \\
17 \\
91 \\
102 \\
251 \\
252 \\
253\end{array}$ & $\begin{array}{l}0 . \\
0 . \\
0 . \\
0 . \\
0 . \\
0 . \\
0 . \\
0 . \\
0 . \\
0 .\end{array}$ & $\begin{array}{l}+0 \\
+0 \\
+0 \\
+0 \\
+0 \\
+0 \\
+0 \\
+0 \\
+0 \\
+0\end{array}$ & $\begin{array}{l}0 . \\
0 . \\
-9.19900+ \\
-7.80000+ \\
-1.48000+ \\
0 . \\
7.25000+ \\
0 . \\
0 . \\
0 .\end{array}$ & $\begin{array}{l}0 \\
0 \\
5 \\
6 \\
7 \\
0 \\
6 \\
0 \\
0 \\
0\end{array}$ & $\begin{array}{r}151 \\
25 \\
19 \\
16 \\
7 \\
19 \\
121 \\
13 \\
13 \\
13\end{array}$ & $\begin{array}{r}158 \\
23 \\
16 \\
16 \\
7 \\
16 \\
272 \\
13 \\
13 \\
13\end{array}$ \\
\hline & & & & & MAT TOTA & & 397 & 547 \\
\hline
\end{tabular}




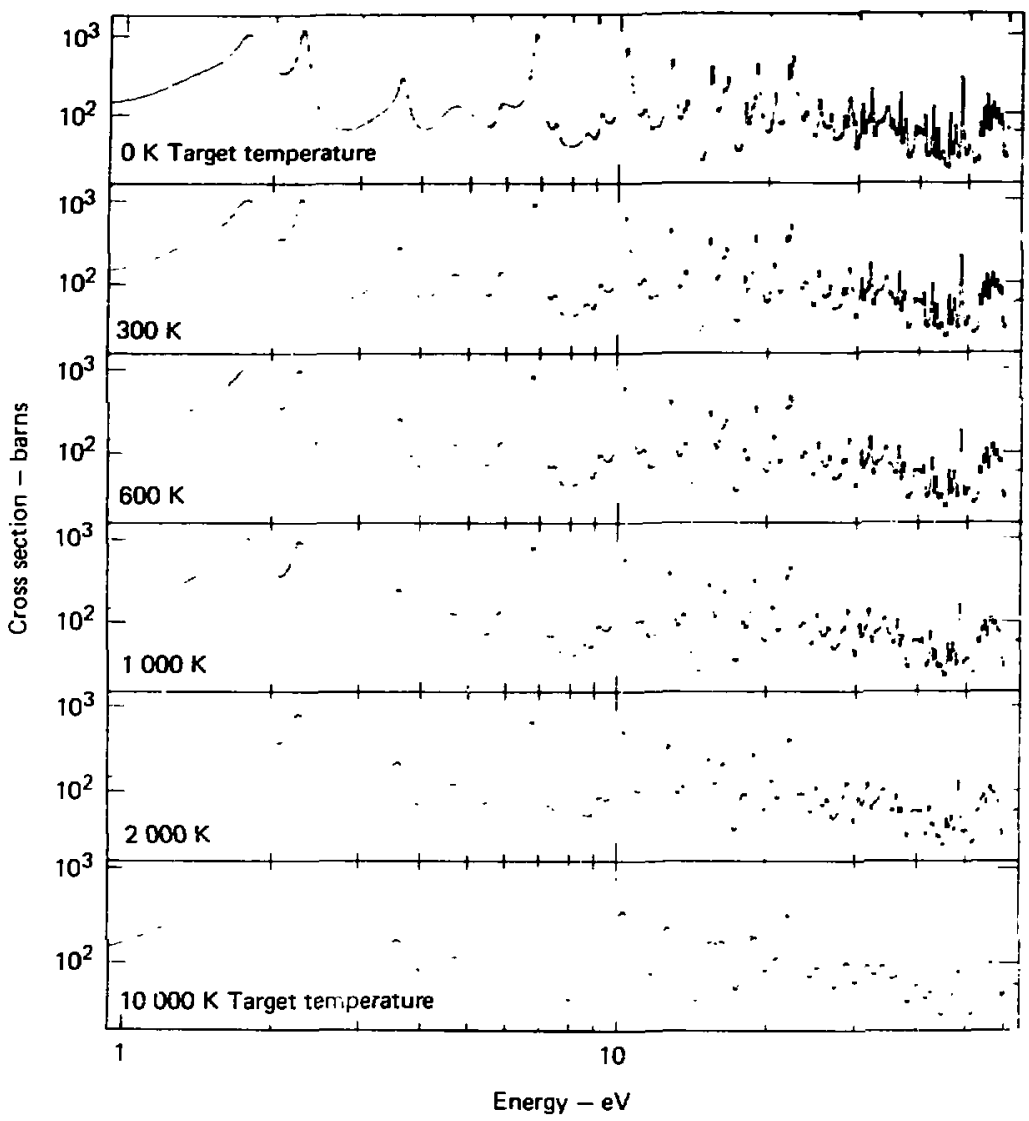

FIG. 2. Doppler broadening of the ${ }^{233} \mathrm{U}$ neutron total cross section to reactor-like tempecatures $(T=300 \mathrm{~K}$ to $10000 \mathrm{~K})$. 


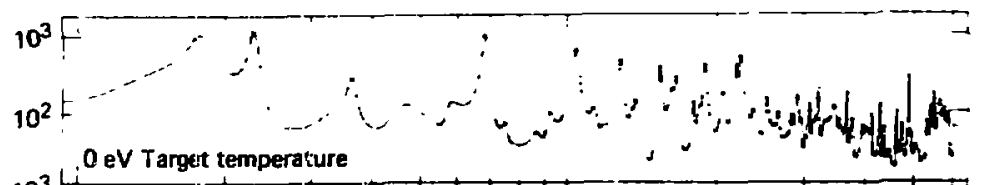

$10^{2}$

$1 \mathrm{eV}$
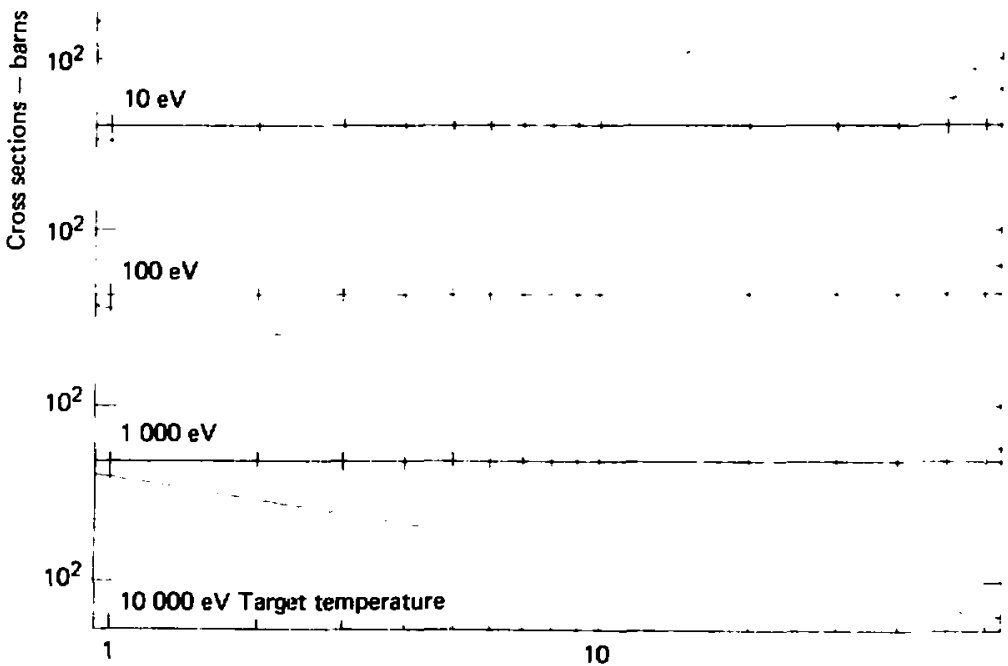

Projectile energy - eV

FIG. 3. Doppler broadening of the ${ }^{233} \mathrm{U}$ neutron total cross section to stellar or CTR-core temperatures $\left(\mathrm{kT}=1 \mathrm{eV}\right.$ to $10 \mathrm{keV} ; \mathrm{T} \approx 1.2 \times 10^{4} \mathrm{~K}$ to $\left.1.2-10^{8} \mathrm{~K}\right)$. 


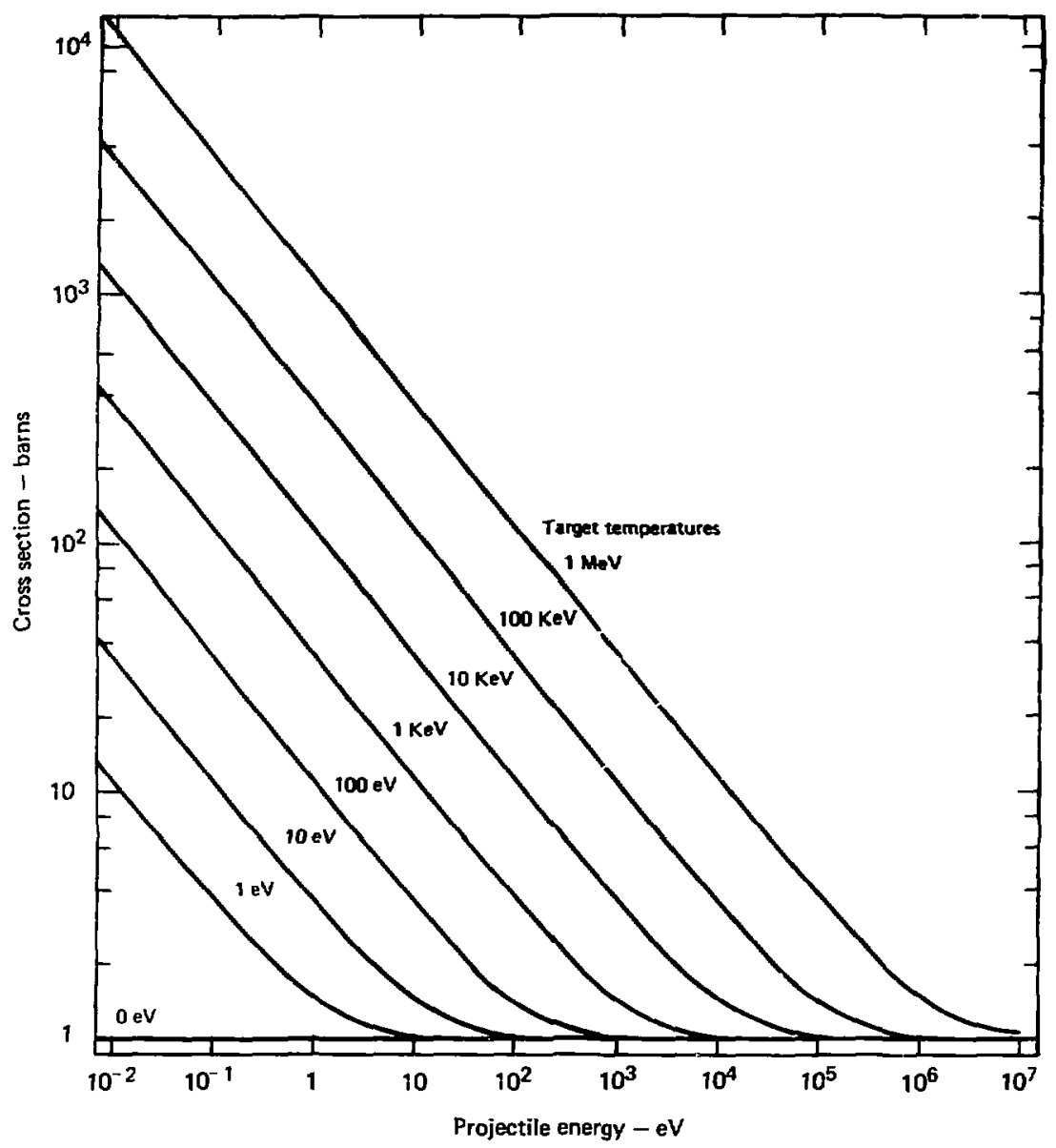

PIG. 4. Doppler broadening of an initially constant cross section to temperatures from $1 \mathrm{eV}$ to $1 \mathrm{MeV}$. The results agree with theoretical predictions over the entire energy range. 


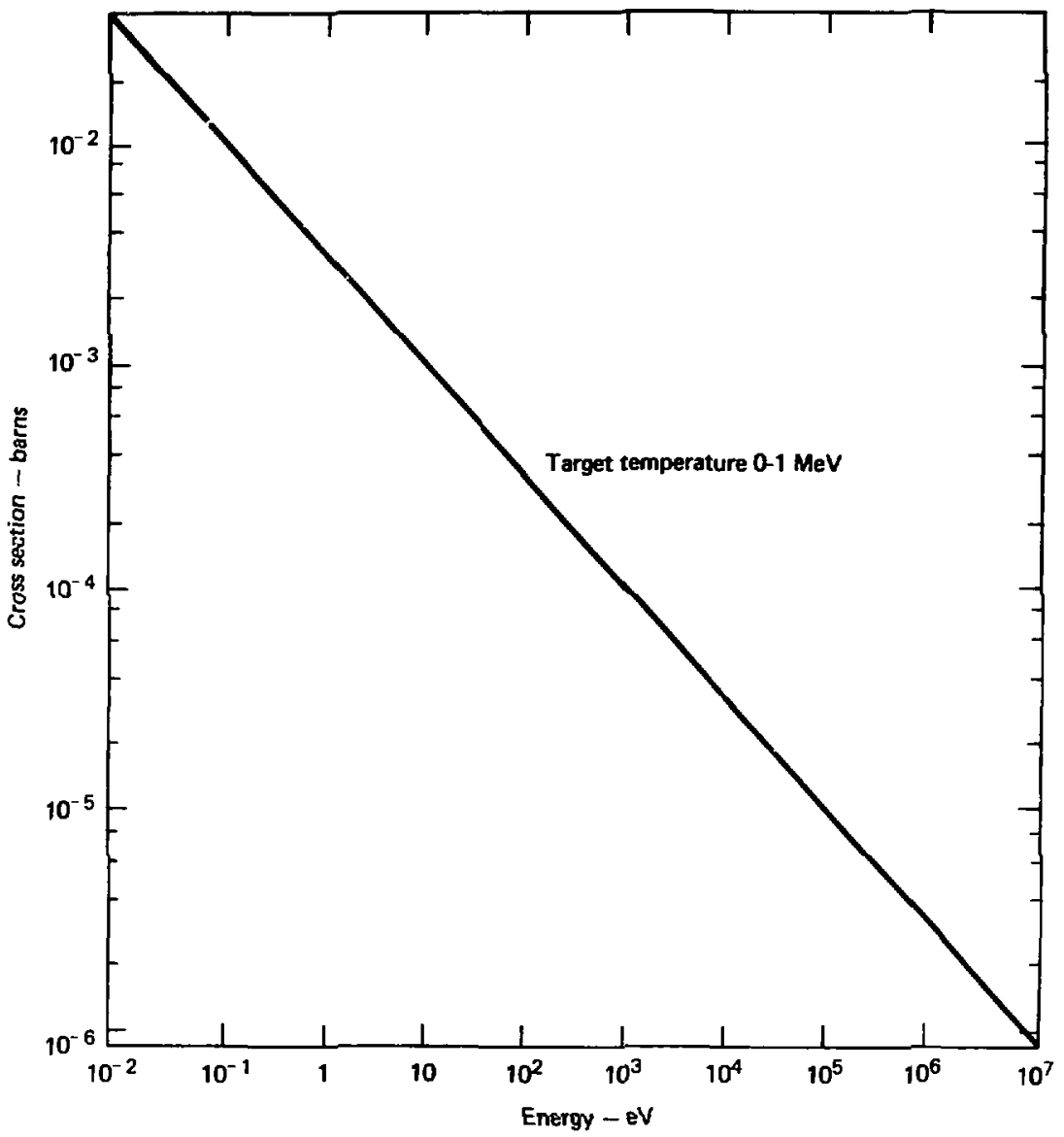

FIG. 5. Doppler broadening of a $1 / v$ cross section. The result should be temperature-independent: to the scale of the figure, it is. There is some temperature dependence, but only for temperatures well above $10 \mathrm{C} \mathrm{kev}$, and oniy for extremely low projectile energies. 
After these files are read from photostore INSIGMl should be renamed INPUT and edited to select the options required.

The program is simall enough (28 000 words) to run at a low prifority duri:t3 the day.

The program will automatically use the disk filenanes described below:

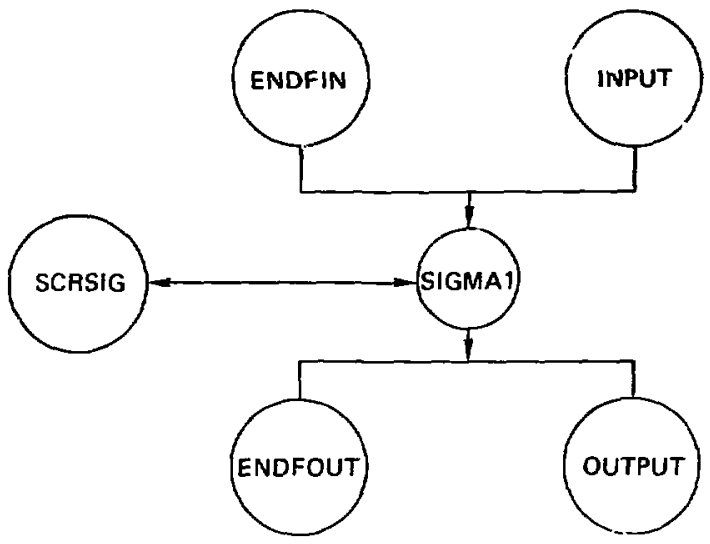

The program is designed to be compiled using either the CHAT compiler (for the CDC-600) or the IIVIC congiler (for the CRAY-1).

CONVERSION TO OTHER TNSTALIATIONS

This revision of the code is designed for use either on a LLI CDC-7600 or CRAY-1, or for export to any other ilsstallation that uses Fortran IV. Most of the coding is in standard Fortran. When an instruction takes different forms for the CDC-7600 or CRAY-I, it is present in three different forms--one for each of the LWL computers and one in standard fortran. Each card in the group of three is inserted as a comment card an? is labelled "CDC-7600," "CRAY-1," or "EXPORT" (this last label designates any machine using standard Fortran). 
To use the code on any given computer activate the appropriate instruction in each set by elininating the conment-card identifier " $\mathrm{C}$ " and the 1abel, and leave the other two instructions in the set as inactive cornent cards.

In particular see the following subroitines, which contain machinedependent coding:

DROPIT At wr this subroutine creates a copy of the loaded program, which is then execitmi; the original program is not affected. In Fortran IV the subroutine does nothing and simply returns.

IBLOCK This routine does the scratch 1/0; in Fortran IV this is equivalent to binary I/O. Operation of SIGMl can be greatly improved by using the most efficient scratch $I / 0$ available at your installat:on.

IOFILE Opens, closes, creates, and destroys disk files. In Fortran IV the subroutine simply returns.

This use of subroutines $f(x) I / O$ will be maintained in future versions of this code. Therefore it is recomended that, instead of replacing the calls to these subroutines, you supply equivalent subroutines for your computer. Your versions of DROPIT, IBLOCK, and IOFILE will be compatible with all future versicns of this code and this will minimize your maintena:sce froblem. Note that the se same routines are also used by LINEAR, ${ }^{2}$ RECENT, ${ }^{7}$ and GROUPIE, ${ }^{8}$ and, once converted, they can be used in all four programs.

\section{ACKYOWLEDDGENTS}

Many people contributed to the developrent of the SIGMAl code. I particularly acknowledge the contributions of R. J. LaBauve, R. E. MacFarlane, and P. Soran of Los Alamos scientific Laboratory, and C. R. Weisbin, J. E. White, and R. Q. Wright of Oak Ridge National Laboratory. 
Many people contributed useful suggestions for improvenents and corrections to be included in the 1978 and 1979 revisions of sItwAl. In particular I acknowledge the contributions of Wolfgarg Rathenstein, the Techition, Haifa, Israel; Leo Levitt and Phil Rose, Brookhaven National Laboratory; Bob Howerton, Lawrence Livermore Laboratory; John E. White, Oak Ridge National taboratory; and the staff of the argonne Code Center. I thank P. พ. Murphy of our Technical Information Department for the excellent job the has done in editing this report. 


\section{REFERGIXES}

1. D. Garber, C. Dunford, and S. Pearlstein, Data Format and Procecures for the Evaluated Nuclear Data File, BNDF, Brookhaven National Laboratory, Upton, NY, BNL-NCS-50496 (WNDF-102) (1975).

2. D. E. Cullen, Program LTNEAR (Verson 79-1): Linearize Evaluated Data in the Evaluated Nuclear Data File/Versica B (BNDE/B) Format, Lawrence Livermore Laboratory, Livermora, CA, UCRI-50400, Vol. 17, Part A (1978).

3. D. E. Cullen and C. R. Weisbin, Mucl, Sci. Eng. 60, 199-229 (1976).

4. R. V. Meghreblian and D. R. Holmes, Reactor Analysis (MoGraw-Bill Book Company, New York, 1960), p. 137.

5. R. J. Howerton, et al., The LLL Evaluated Nuclear Data Library (ENDL), Lawrence Livermore Laboratory, Livermore, CA, tCRL-50400, vol. 15, Parts $A, B$, and $C$ (1976).

6. D. E. Cullen, "Program DICTION," in Description of the ENDF/B Processing Codes and Retrieval Subroutines, Brookhaven National Laboratory, Upton, NY, BNL-50300 (ENDF-110) (1971).

7. D. E. Cullen, Program RECENT (Version 79-1): Reconstruct Energy Dependent Cross Sections From Resonance Parameters in the Evaluated Nuclear Data File/Version B (BNDF/B) Format, Lawrence Livermore Laboratory, Livermore, CA, UCRL-50400, Vol. 17, Part C (1979).

8. D. E. Cullen, Program GROUPIE (Version 79-1): Calculation of Bonderenko Self-shielded Cross Sections and Multiband Parameters from Evaluated Data in the Evaluated Nuclear Data File/Version $B$ (BNDF/B) Format, Lawrence Livermore Laboratory, Livermore, CA, UCRL-50400, vol. 17, Part D (1979). 